\title{
Gestão democrática do ensino público e o município
}

\author{
Democratic management of public education and the municipality
}

Elton Luiz Nardi*

\section{Resumo}

O artigo tem por objetivo refletir sobre desafios da materialização da gestão democrática do ensino público no plano político-institucional dos municípios, nomeadamente, no âmbito dos respectivos sistemas de ensino. Enfoca a questão da democracia enquanto processo e o contexto brasileiro, de modo a realçar o lugar da bandeira da democratização da gestão educacional, os principais artefatos legais a ela associados e a emergência do sistema municipal de ensino enquanto instância implicada na promoção da gestão democrática do ensino público. $\mathrm{Na}$ esteira desse debate, traz apontamentos sobre a especificidade da ação dos sistemas municipais e sobre tensões e desafios que circundam a adoção de princípios e valores democráticos. Destacando o protagonismo do sistema municipal de ensino no campo da normatização da gestão democrática, conclui que tal movimento encerra complexidade e contradições, numa difícil combinação de resultados que, por um lado, informam avanços, continuísmos e até retrocessos na dinâmica de democratização e, por outro, realçam a centralidade do ingrediente da participação política na constituição de bases político-institucionais verdadeiramente comprometidas com a gestão democrática do ensino público.

Palavras-chave: Ensino público. Gestão democrática. Município. Sistema municipal de ensino.

\section{Abstract}

The article aims to reflect about challenges of the implementation of democratic management of public education at the political-institutional level of municipalities, in particular within their respective educational systems. It focuses on the issue of democracy as a process and the Brazilian context, in order to highlight the place of the flag of democratization of educational management, the main legal artefacts associated with it and the emergence of the municipal educational system as an entity involved in promoting the democratic management of public education. It still brings notes about the specificity of the action of municipal systems and about tensions and challenges that surround the adoption of principles and democratic values. Highlighting the role of the municipal educational system in the field of regulation of democratic management, it concludes that this movement contains complexity and contradictions, in a difficult combination of results that, on the one hand, inform advances, continuities and setbacks in the dynamics of democratization and, on the other hand, it highlights the centrality of the ingredient of political participation in the constitution of bases political-institutions that are truly committed to the democratic management of public education.

Keywords: Public Education. Democratic management. Municipality. Municipal educational system.

Recebido em: 16/02/2017 - Aprovado em: 10/06/2017

http://dx.doi.org/10.5335/rep.v24i2.7412

Doutor em Educação pela Universidade do Vale do Rio dos Sinos (Unisinos). Professor titular do Programa de Pós-Graduação em Educação da Universidade do Oeste de Santa Catarina (Unoesc). E-mail: elton.nardi@unoesc.edu.br 


\section{Introdução}

Em educação, costumamos apontar a década de 1980 como uma das mais promissoras em realizações, haja vista a mobilização para a construção de um projeto educacional inscrito na disputa política pela redemocratização do país. Tempo em que a bandeira da participação ganhou impulso notável, afigurando-se como um recurso de qualificação da atividade política, que, também, passou a lançar questionamentos sobre o sentido atribuído à política como atividade exclusiva de políticos profissionais bem como aos velhos aparatos políticos e à sua desconexão com a sociedade (NOGUEIRA, 2015). Tempo de disputas pelo próprio significado de democracia no país.

Fruto dessa importante mobilização política, a Constituição federal de 1988 (BRASIL, 1988) firmou o princípio da gestão democrática do ensino público, ainda que tal incorporação deva ser compreendida como parte de um leque de demandas não necessariamente concentrado nos setores progressistas.

Conforme registra Cunha (1995), tal mobilização esteve relacionada à luta tanto pela democratização da educação como pela promoção da descentralização da arrecadação tributária, esta última associada à ampliação da autonomia dos entes federados. É nesse mesmo contexto que ocorreu a ascensão do município à condição de ente federativo, entidade com autonomia política, administrativa e financeira e com capacidade de auto-organização, condição da qual também decorreu sua incumbência de organizar o sistema próprio de ensino.

É justamente no enlace desses elementos contextuais com o tema da democratização da gestão educacional que o presente trabalho se concentra, tendo por objetivo refletir sobre desafios da materialização da gestão democrática do ensino público no plano político-institucional dos municípios, nomeadamente, no âmbito dos respectivos sistemas de ensino.

Assim, na primeira parte do texto, as atenções se voltam à questão da democracia enquanto processo e ao contexto brasileiro, tendo em vista explorar elementos do curso histórico que permitam compreender o lugar da bandeira da democratização da gestão educacional e os principais artefatos legais a ela associados, assim como a emergência do sistema municipal de ensino enquanto instância implicada na promoção do princípio constitucional da gestão democrática do ensino público.

A segunda parte, na esteira das reflexões que enfocam a expectativa no protagonismo municipal com vistas à promoção da gestão democrática, traz apontamentos sobre a especificidade da ação dos sistemas municipais, as tensões e os desafios que circundam a adoção de princípios e valores democráticos, especialmente, no tocante à promoção da participação política como recurso fundamental para o exercício do poder decisório que se quer compartilhado entre o Estado e a sociedade. 
Por fim, a última seção destina-se à apresentação de algumas notas conclusivas sintonizadas com o objetivo do trabalho, com as quais buscamos realçar desafios mais ou menos imediatos relacionados à constituição, pelos municípios, de bases político-institucionais comprometidas com a gestão democrática do ensino público.

\section{Democratização e o contexto brasileiro: algumas notas}

Entendemos a democracia como um processo e não um estado, motivo pelo qual, na linha de análise de Coutinho, será mais adequado falarmos em democratização, tendo em conta que esta só se realiza na combinação entre "a socialização da participação política com a socialização do poder [...]" (2003, p. 17, grifo do autor).

A participação política, por sua vez, é entendida como via com potencial para aperfeiçoar as condições de democratização da gestão, sem que passe ao largo desse entendimento a consciência de que tal objetivo disputa lugar com recursos e estratégias de simplificação dessa via, o que inclui a questão da qualidade da representação política possibilitada. Um exemplo dessa tendência é o fato de o cidadão pressionar por mais participação e, ao mesmo tempo, ser barrado no terreno em que as decisões são tomadas (NOGUEIRA, 2015).

Conforme propõe Bordenave (1985), compreendemos a participação como o envolvimento das pessoas na construção da realidade político-social, entendido como a ação política em processos decisórios sobre assuntos de interesse público, que se afigura na identificação de problemas e necessidades comuns, no acompanhamento, no controle, na fiscalização e na avaliação dos processos da prática social que se tem em causa (LIMA, 2003).

Atentos a essa perspectiva de democratização como movimento, entendemos que a abertura democrática da década de 1980 - ainda que a ideia de uma transição democrática tenha a marca da ambiguidade (SAVIANI, 2006) - constitui-se em palco do maior envolvimento dos atores sociais na busca por atenção e legitimidade do poder público brasileiro em relação aos interesses e às necessidades comuns, evidência de uma melhor compreensão, por esses mesmos atores, de que a democracia é um valor historicamente determinado. Conforme descreve Oliveira, vigorava nessa década um sentimento de que "a caução do apoio popular, dos movimentos que haviam sido criados mesmo na própria ditadura, eram suficientes para pautar a agenda, a ação e o comportamento do novo governo" $\left(2003\right.$, p. 46). ${ }^{1}$

Tratou-se de um tempo de emblemáticas manifestações que aprofundaram reivindicações democráticas pelas diretas, conectadas a grandes questões sociais e econômicas experienciadas pelo país (WEFFORT, 1984). Foi, também, um tempo 
marcado pela reivindicação por canais de participação e por recursos de controle social, destinados a operar a ação popular sobre o Estado, notadamente, no sentido da garantia dos direitos sociais. Do ponto de vista da organização do campo educacional brasileiro, não restam dúvidas de que a década de 1980 foi uma das mais fecundas da nossa história (SAVIANI, 2008).

Conforme observa Oliveira (2003), nesse período, o Estado foi desafiado pelos movimentos sociais justamente no que ele era mais frágil: as políticas sociais. Importa considerar que, nesse contexto, a bandeira da gestão democrática da escola pública constituía parte importante do projeto abraçado pelo movimento em relação às políticas públicas para o setor educacional, do debate político mais amplo sobre o direito de participação da sociedade civil como condição de uma cidadania ativa (KRAWCZYK, 2008).

Um dos vetores desse projeto foi a preocupação com o significado social e político da educação, com base no qual era imperativa a busca por uma escola pública de qualidade para toda a população e atenta às necessidades da maioria (SAVIANI, 2008). Com essa bandeira principal, sublinha Neves (2003), as defesas do campo democrático de massas, sob o signo da democratização da educação escolar, enfatizavam um patamar mais elevado do acesso e da permanência das crianças das camadas populares nas escolas de ensino fundamental.

No entanto, ainda que a inclusão do princípio da gestão democrática na Constituição federal de 1988 - inédito na história constitucional do Brasil - tenha sido lastreada pelo clima que emanava do movimento pela democratização do país na mesma década, não se pode perder de vista que as transformações políticas e econômicas operadas nos anos de 1980 e 1990 tenderam tanto à redemocratização política quanto à liberalização e à privatização do público.

Esta última tendência - a privatização do público -, conforme sublinha Benevides (2003), seguirá informando uma dolorosa realidade da tradição política brasileira, que favorece a constituição de um simulacro da democracia no país (OLIVEIRA, 2003). ${ }^{2}$ Daí a conclusão que nos oferece Ianni (2004) sobre a história do Brasil moderno e a simbolização de rupturas, retrocessos e aberturas ao longo do século XX. Para o autor, embora tenham sido registradas modificações na sociedade em termos sociais, econômicos, políticos e culturais, isso não significa que sempre tenham sido operadas para melhor, em favor dos interesses da maioria.

Assim posto, a busca de um conteúdo para a relação entre democracia e educação escolar, a partir dos anos 1990, segundo Neves (2003), não pode prescindir de nossa atenção sobre duas de suas marcas principais no âmbito da política neoliberal, quais sejam: o caráter antipopular das políticas sociais, possível de ser apreendido na análise de ingredientes como a privatização, a focalização, a descen- 
tralização (de encargos) e a participação (concentrada em interesses específicos); e a direção dada às ações educacionais, cuja base se situa em uma cultural empresarial. À luz dessa cultura, desponta o modelo gerencial de gestão, pautado na busca por eficiência, redução e controle dos gastos, demanda de melhor qualidade do serviço público e descentralização dos serviços, de modo que as atenções e as metas sejam deslocadas do processo para o produto. Como escreve Lima (2015), trata-se do surgimento da hierarquia, do mercado competitivo e da cooperação em complexas combinações.

Sendo a educação assunto do Estado e matéria central do novo modelo de desenvolvimento de escala mundial, as marcas brevemente sumarizadas neste texto reforçam o fato de que a política educacional segue profundamente implicada e interferida por esses processos, principalmente quanto à gestão, um dos domínios da política do setor que tem sido alvo das mais profundas transformações patrocinadas pela agenda neoliberal, transformações essas fundadas no discurso da técnica e da agilidade administrativa (OLIVEIRA, 2000).

Como referido, são transformações que ocorrem sob a influência de valores autoritários (AZEVEDO, 2000), que renovam as bases da já bem conhecida dominação política de ordem patrimonial (FAORO, 1987), há muito vigente entre nós. A esse respeito, mencionando o ciclo de globalização do capitalismo que se processa no fim do século XX, Ianni (2004) refere justamente a "modernização" das oligarquias, pontuando que os remanescentes das oligarquias patriarcais no país - as "oligarquias eletrônicas" - readquiriram papéis políticos na intermediação entre diretrizes neoliberais e raízes socioculturais e clientelistas remanescentes, do que resultam bases sociopolíticas e econômicas para o bloco no poder, consoante o compromisso desse bloco com a globalização neoliberal.

Para Höfling (2001), entretanto, se considerarmos que, em decorrência dos poucos avanços e dos insistentes retrocessos na condução dos assuntos públicos, a discussão sobre a promoção de mecanismos e estruturas democratizantes segue sendo reforçada no país, não podemos ignorar o papel que a política educacional tem a desempenhar, numa sociedade desigual e heterogênea, para a democratização da sua estrutura e a formação do cidadão. Também porque, nesse terreno, foram acumuladas iniciativas marcadas pela pluralidade e situadas em realidades sociais e políticas que contrariam os modelos alicerçados no pensamento único, a exemplo das experiências de governos subnacionais, como é o caso de muitos municípios brasileiros, que operaram formas participativas na gestão educacional carregadas de importante significado político. ${ }^{3}$

É na esteira dessa expectativa que entendemos o acolhimento da gestão democrática do ensino público, pela Constituição federal de 1988 (art. 206, inciso VI), 
como um importante passo ao projeto de democratização na educação. Na síntese de Cury:

A conquista do princípio constitucional da gestão democrática, em 1988, em estabelecimentos oficiais dos sistemas de ensino representou e continua representando um passo admirável para a vida democrática de nossos estabelecimentos e para os próprios sistemas de ensino. Ela implica a participação cidadã dos interessados e a necessidade de prestação de contas por parte dos dirigentes e dos próprios docentes quanto aos objetivos da educação escolar (2005, p. 9).

O fato é que a condição constitucional conferida à gestão da educação básica pública, apesar de se tratar de importante conquista, não se confunde com a garantia de condições necessárias à materialização do princípio consagrado. Isso também passa pelo plano legal infraconstitucional, afinal, a Lei de Diretrizes e Bases da Educação Nacional (LDB), Lei nº 9.394, de 20 de dezembro de 1996, não definiu o significado, a extensão e os mecanismos para a implementação do princípio de gestão democrática do ensino público. Diferente disso, a tarefa recaiu aos sistemas de ensino (art. 14), aos quais cabe definir normas sobre a matéria, de acordo com suas peculiaridades e observados os princípios da participação dos profissionais da educação na elaboração do projeto pedagógico da escola e da participação das comunidades escolar e local em conselhos escolares ou equivalentes.

Também, a recente Lei no 13.005 , de 25 de junho de 2014, que aprovou o Plano Nacional de Educação (PNE) para o período 2014-2024, aponta para a mesma direção, embora tenha avançado com a fixação do prazo de dois anos contados da publicação da lei para tal disciplinamento por parte dos estados, do Distrito Federal e dos municípios (art. 9º).

Pode-se dizer, portanto, que a materialização da gestão democrática em nível institucional, em face do caminho delineado para a fixação das regras do processo de democratização, passa necessariamente pela regulamentação expressa em norma posterior à constitucional, no âmbito dos sistemas de ensino. Nesse sentido, o que está em causa é a qualidade política dessa providência, ainda que a materialização da gestão democrática, conforme mencionado, dependa de outras condições associadas.

\section{0 município: sistema de ensino e democratização da gestão}

Com o advento do modelo federativo brasileiro, consagrado pela Constituição federal de 1988, o município foi ascendido à condição de ente da federação, como entidade com autonomia política, administrativa e financeira e com capacidade de auto-organização. Nessa perspectiva, foi-lhe creditada autonomia no campo 
educacional, com o direito de organização do sistema próprio de ensino, havendo vinculação de percentuais de recursos e outras definições que reforçam a disposição da Constituição federal para a descentralização política. Todavia, isso não significa a neutralização das possibilidades de conflitos entre a ordem jurídica estabelecida e a realidade concreta, pois os resultados esperados do protagonismo municipal dependem de vários fatores, como o grau de articulação social, a dinâmica política das comunidades locais e as expectativas da sociedade civil em relação à ação do Estado (MENDONÇA, 2000).

Consoante esse novo modelo organizativo, os sistemas municipais de ensino passaram a se constituir em instância com fundamento constitucional, como consequência do caráter de pessoa jurídico-política de direito interno adquirido pelo município. De acordo com o Parecer CNE/CEB no 30/2000, um sistema de ensino compreende um conjunto de:

[...] campos de competências e atribuições voltadas para o desenvolvimento da educação escolar que se materializam em instituições, órgãos executivos e normativos, recursos e meios articulados pelo poder público competente, abertos ao regime de colaboração e respeitadas as normas vigentes (BRASIL, 2000, p. 13).

Portanto, com a criação legal de seus órgãos normativo e executivo, além do que dispõem os artigos 11 e 18 da LDB, o município imprime sua forma própria de entidade política autônoma que, no âmbito da educação escolar, integra o sistema federativo brasileiro (BRASIL, 2000).

À luz da base legal nacional que fundamenta a nova circunstância da esfera municipal no campo educacional, as incumbências dos municípios podem ser compreendidas, basicamente, em duas dimensões: a que pressupõe a instituição do sistema próprio de ensino em seu modus operandi e a que independe dessa instituição, no caso de a opção ser pela integração ao sistema estadual de ensino ou pela composição, com ele, de um sistema único de educação básica.

De acordo com o artigo 11 da atual LDB, em se tratando da opção pela organização do sistema próprio de ensino, destacam-se as atribuições de baixar normas complementares para o sistema (inciso III) e autorizar, credenciar e supervisionar os estabelecimentos a ele integrados (inciso IV). Já as incumbências que independem da organização do sistema, haja vista o dever do Estado com a educação pública escolar (art. $4^{\circ}$, incisos I ao IX), ficam assim compreendidas: organizar, manter e desenvolver os órgãos e as instituições oficiais, integrando-os às políticas e aos planos educacionais da União e dos estados; exercer ação redistributiva em relação às suas escolas; oferecer a educação infantil em creches e pré-escolas e, com prioridade, o ensino fundamental; e assumir o transporte escolar dos alunos da rede municipal. 
No rol das incumbências consagradas pela Constituição de 1988, também, os sistemas municipais de ensino foram incumbidos da definição das normas da gestão democrática do ensino público (art. $3^{\circ}$, inciso VIII), nos termos da atual LDB, mais precisamente, dos artigos 14 e 15, ambos sintonizados com o princípio constitucional. Conforme mencionado, reforça e complementa essa incumbência o disposto na Lei $\mathrm{n}^{\mathrm{o}}$ 13.005, de 25 de junho de 2014:

Art. 9ํㅡㄴ Os Estados, o Distrito Federal e os Municípios deverão aprovar leis específicas para os seus sistemas de ensino, disciplinando a gestão democrática da educação pública nos respectivos âmbitos de atuação, no prazo de 2 (dois) anos contado da publicação desta Lei, adequando, quando for o caso, a legislação local já adotada com essa finalidade (BRASIL, 2014).

Assim posto, importa assinalar que a gestão da educação, como campo de formulação e de implementação de políticas de educação e de organização do trabalho educativo, é um processo que ocorre de acordo com determinada orientação política. Esta, por sua vez, é constituída a partir da dinâmica de relações que se desenvolvem nos contextos institucionais interno e externo, com vistas ao atendimento de determinados objetivos. Admite-se, então, que o perfil normativo da gestão democrática do ensino público no âmbito municipal e o que decorrerá dele no campo da prática serão, antes de tudo, expressões de uma vontade política, ampliada ou não, publicamente legítima ou mesmo meramente simbólica.

Destaca-se a ideia de gestão da educação como "um processo político-administrativo contextualizado, através do qual a prática social da educação é organizada, orientada e viabilizada" (BORDIGNON; GRACINDO, 2000, p. 147). Mais que um campo da aplicação de princípios, métodos e técnicas administrativas que lhe atribuem uma roupagem meramente utilitarista, ${ }^{4}$ é um processo de aprendizagem e de luta política construído na especificidade prática educativa enquanto prática social. Como parte desse processo, decorre "a criação de canais de efetiva participação e aprendizado do 'jogo' democrático e, consequentemente, do repensar das estruturas de poder que permeiam as relações sociais e, no seio dessas, as práticas educativas" (DOURADO, 2000, p. 79).

Mas, qual o eixo e o objetivo desse processo de aprendizagem e de luta política? Certamente, trata-se da participação, entendida como recurso fundamental para o exercício do poder de decisão, como a liberdade e a capacidade de os sujeitos decidirem acerca de assuntos de interesse comum e que, portanto, têm por referência

[...] o fortalecimento dos espaços de socialização, de descentralização do poder e de crescente autonomização das decisões [...] [assim como] de articulação do Estado com os sujeitos sociais, que assim se configura em um instrumento de socialização da política [...] (JACOBI, 2000, p. 19). 
De acordo com Le Boterf (1982), a participação na gestão educacional situa-se em um contexto de possibilidades e de limites que repercute na sua significação, posto que as alternativas surgem "num equilíbrio instável de compromissos entre forças presentes e os interesses em jogo" (FALEIROS, 2009, p. 82, grifo do autor). Por isso a ideia de autonomia como um campo de forças que se confrontam e se equilibram (BARROSO, 2000).

Acentua-se que a participação referida é a que reflete o envolvimento das pessoas na construção da realidade social, a partir de necessidades reais, por meio da tomada de decisões e de práticas que decorrem dessas decisões. Seguindo Bordenave (1985), diz respeito à intervenção das pessoas nos processos dinâmicos que constituem ou modificam a história da sociedade, para o que são requeridas análises bem fundamentadas sobre orientações políticas vigentes, assim como argumentos sólidos em favor da democracia (ANGUS, 2001).

Acerca da essencialidade da participação, também Apple e Beane (1997) consideram indispensável a observância de determinadas condições, dentre as quais destacam: o livre fluxo de ideias, para que as pessoas estejam sempre bem informadas; a confiança nas capacidades individual e coletiva das pessoas de resolver problemas; a reflexão e a análise crítica como práticas para avaliação de ideias, problemas e políticas; a preocupação com o bem comum, com a dignidade e os direitos e com as minorias; a compreensão de que a democracia é tanto um ideal a ser buscado, como um conjunto de valores a serem vividos e que devem regular nossa vida enquanto povo; e a organização de instituições sociais voltadas à promoção e à ampliação do modo de vida democrático.

É na perspectiva da promoção e da ampliação que destacamos a importância da constituição de espaços e mecanismos de participação enquanto lugares do plano coletivo, nos quais se processa o exercício do poder decisório sobre assuntos de pertença ao público. Vê-se, pois, que a constituição e a legitimação desses espaços e mecanismos são matérias a serem enfrentadas tanto no âmbito do processo de traçado normativo atinente à gestão democrática do ensino público, como no âmbito das práticas concretas de participação no seio do sistema municipal de ensino. $\mathrm{O}$ contexto é o mesmo: o compromisso político com a democratização.

Como expressão de condições favoráveis à participação, a constituição de determinados espaços e mecanismos institucionalizados vem se destacando nos últimos tempos, como expressão de um ambiente de participação que tenciona a democracia representativa e realça a democracia direta (SANTOS JUNIOR; RIBEIRO; AZEVEDO, 2004). Dentre esses espaços e mecanismos, estão compreendidos os conselhos, o orçamento participativo, os fóruns, as conferências e outras formas pelas quais as pessoas têm condições de se manifestar e construir suas identidades 
pessoais e coletivas (STRECK; ADAMS, 2006). Somam-se a eles a eleição para escolha de dirigentes escolares (PARO, 1997; DOURADO, 2000) e a construção do projeto político-pedagógico (VEIGA, 1995), já amplamente discutidas na literatura educacional brasileira.

Em suma, considerando-se conquistas como o princípio constitucional da gestão democrática do ensino público, o crescente movimento político que destaca fatores determinantes das opções normativo-institucionais em nível municipal e o lastro do debate denso construído ao longo das últimas décadas, com vistas à promoção de uma maior pertinência social da ação do Estado, podemos dizer que seguem acesas as apostas no aprimoramento de condições que viabilizem ampliar, com qualidade política, a democratização da gestão educacional.

Contudo, seja pela baixa frequência de experiências municipais caracterizadas por uma maior radicalidade democrática na gestão educacional, nomeadamente pela via da ampliação concreta e efetiva da participação política, ${ }^{5}$ seja pela proliferação de iniciativas que se situam, convenientemente, no escopo de práticas tradicionais e até abertamente contraditórias (JACOBI, 2000), é certo que a construção democrática entre nós continua sendo um desafio de proporções históricas.

\section{Anotações conclusivas}

A reflexão lançada neste texto buscou visibilizar desafios quanto à materialização da gestão democrática do ensino público no plano político-institucional dos municípios brasileiros, mais especificamente, com o advento dos sistemas municipais de ensino, figura inaugurada pela Constituição federal de 1988, consoante a ascensão do município à condição de ente federativo, e mais precisada em dispositivos da atual LDB.

Conforme proposto, tal reflexão foi tecida no enlace de elementos contextuais que caracterizam a experiência brasileira, em seu intrincado processo de construção democrática, com o tema da democratização da gestão educacional, que integrou a agenda dos movimentos sociais dos anos 1980 com vistas à redemocratização do país.

No que responde ao debate sobre a questão da democracia e a experiência brasileira nesse campo, buscamos assinalar que a firmação da bandeira da gestão democrática do ensino público, no contexto histórico do movimento pela redemocratização do país, ocorreu sob o pressuposto da participação política articulada à socialização do poder. A dissonância desse pressuposto de base com imperativos da ordem capitalista - ainda que a ideia de plena realização da democracia implique superar a ordem social capitalista (COUTINHO, 2003) - e com a lógica da priva- 
tização do público, que se "moderniza" e renova ao longo do tempo, foi e continua sendo um desafio de grandes proporções, afora um ato de coragem.

A par dessa circunstância desafiadora - em muitos casos, imbricada nela -, buscamos assinalar a existência de outros fatores que implicam a construção democrática e que residem no campo da mobilização dos atores sociais. Dizem respeito, conforme Moisés, ao processamento da "complexa pluralidade de interesses, identidades e objetivos que mobilizam os atores sociais [e que] depende de processos demorados e contraditórios de elaboração coletiva" (1995, p. 84). Afinal, continua o autor, a "adoção de procedimentos capazes de potencializar esses processos através de mecanismos compatíveis supõe uma difícil negociação entre contendores que têm concepções e, principalmente, expectativas diferentes sobre a dinâmica democrática" (1995, p. 84).

Ainda assim, o mesmo percurso histórico do qual colhemos as lições que tocam esses desafios vem sendo palco de experiências situadas em realidades sociais e políticas que, como dissemos, contrariam ou têm potencial para contrariar modelos alicerçados no pensamento único. $\mathrm{O}$ balanço dessa realidade marcada por contradições oportuniza-nos reforçar a tese da democracia como movimento e como tarefa sempre inconclusa.

Então, pensar a gestão democrática da educação como parte de um projeto de educação e de sociedade requer que também a consideremos uma tarefa social e politicamente complexa. Por isso o reconhecimento de que as conquistas que, em dado momento histórico, estiveram no horizonte desse projeto constituem hoje peças importantes para os próximos desdobramentos. A inclusão do princípio da gestão democrática do ensino público é, indubitavelmente, uma dessas importantes peças.

Posto o desafio da materialização desse princípio e, como procuramos assinalar, a dinâmica controversa determinada pela legislação atual - situada na aposta de que seja orientada fundamentalmente por normatização no âmbito dos sistemas de ensino -, trouxemos à cena a questão do protagonismo do sistema municipal de ensino no campo dessa normatização. Ainda que esse fenômeno seja relativamente recente, pois está mais diretamente situado no período pós-LDB de 1996, diversos estudos oportunizam perceber que tal movimento também encerra complexidade e contradições, numa difícil combinação de resultados que informam avanços, continuísmos e até retrocessos na dinâmica de democratização.

Por isso tudo, pensamos que o projeto de gestão democrática da educação, na sua relação com a atribuição conferida ao novel sistema municipal de ensino, requer que sigamos empenhados na promoção da participação política, dada sua essencialidade para o processo de democratização que temos abraçado no país, no plano das lutas por uma escola pública e de qualidade para todos. Uma participação 
que, na prática, possibilite-nos (re)pensar as estruturas de poder, jogando luz sobre algumas outras peças que podem, segundo os pressupostos democráticos que defendemos, ampliar as condições concretas para que os atores sociais participem mais efetivamente dos processos decisórios atinentes à educação pública do nosso país.

\section{Notas}

1 Ciavatta registra que, na linha de muitos analistas, a transição da ditadura para o regime democrático ocorrida no Brasil é a mais longa que se conhece. "Se tomarmos como marco o 'fechamento' efetivo do sistema em 1968 e o processo de 'abertura' anunciado pelo Governo a partir de 1978, tivemos, até 1988, processos da mesma duração, dez anos de cada um, um tempo tão longo que demanda reflexão sobre a forma específica com que a transitoriedade se apresentou" (2003, p. 88).

2 Escreve o autor: "[...] temos instituições formais, eleições livres, até alternância do poder, mas isso parece pouco com a democracia, porque, de fato, estamos sendo conduzidos, há muito, ao reino da não alternativa" (OLIVEIRA, 2003, p. 48).

3 Cunha (1995) refere experiências do final dos anos 1970 e início dos anos 1980 nos municípios de Boa Esperança (ES), Lages (SC) e Piracicaba (SP), que, de diversas maneiras, anteciparam políticas educacionais voltadas às classes populares e, também, ganharam notoriedade pela ênfase à participação das comunidades na gestão da educação pública. Gadotti e Jacobi (1994) e Arelaro (1999) relatam experiências nos municípios de São Paulo (1989 a 1992) e Diadema (1993 a 1996), com a ampliação de espaços de participação decisória da sociedade sobre a política educacional.

4 Em boa medida, esse entendimento justifica certas distinções, na literatura educacional, no uso dos termos "administração" e "gestão". "Algumas vezes gestão é apresentada como um processo dentro da ação administrativa; outras vezes seu uso denota apenas a intenção de politizar a ação administrativa, noutras apresenta-se como sinônimo de 'gerência', numa conotação neotecnicista dessa prática e, em muitos momentos, gestão aparece como a 'nova' alternativa para o processo político-administrativo da educação [...] há uma reação (por vezes muito forte) ao termo administração da educação, como consequência da forma descomprometida, 'neutra' e tecnicista como ela se desenvolveu na década de 70 [...]" (BORDIGNON; GRACINDO, 2000, p. 147).

5 Em trabalho que enfoca estudos sobre a reforma educacional no Brasil nos anos 1990, Krawczyk e Vieira (2008) referem que experiências municipais de gestão democrática, levadas a efeito na década de 1990, com inspiração nas propostas da década de 1980, nem sempre se efetivaram, haja vista a descontinuidade das práticas e a dificuldade das autoridades municipais em lidar com conflitos e desenvolver uma cultura participativa, antes encetada pela intencionalidade de promover a participação popular por meio da institucionalização de espaços coletivos, como fóruns e conselhos.

\section{Referências}

ANGUS, Lawrence. Participación democrática o gestión eficiente del centro: la situación social y política de la autonomía escolar. In: SMYTH, John (Ed.). La autonomía escolar: una perspectiva crítica. Madrid: Akal, 2001. p. 19-44.

APPLE, Michael W.; BEANE, James. Escolas democráticas. São Paulo: Cortez, 1997.

AZEVEDO, Janete Maria Lins de. O Estado, a política educacional e a regulação do setor educação no Brasil: uma abordagem histórica. In: FERREIRA, Naura Syria Carapeto; AGUIAR, Marcia Ângela da S. (Org.). Gestão da educação: impasses, perspectivas e compromissos. 4. ed. São Paulo: Cortez, 2004. p. 17-42.

ARELARO, Lisete Regina Gomes. A ousadia de fazer acontecer: o direito à educação: algumas reflexões sobre a experiência de gestão nas cidades de São Paulo (1989/92) e Diadema (1993/96). In: 
OLIVEIRA, Dalila Andrade; DUARTE, Marisa R. T. (Org.). Política e trabalho na escola: administração dos sistemas públicos de educação básica. Belo Horizonte: Autêntica, 1999. p. 191-207.

BARROSO, João. O reforço da autonomia das escolas e a flexibilização da gestão em Portugal. In: FERREIRA, Naura Syria Carapeto (Org.). Gestão democrática da educação: atuais tendências, novos desafios. 2. ed. São Paulo: Cortez, 2000. p. 11-32.

BENEVIDES, Maria Victoria. A construção da democracia no Brasil pós-ditadura militar. In: FÁVERO, Osmar; SEMERARO, Giovanni (Org.). Democracia e construção do público no pensamento educacional brasileiro. 2. ed. Petrópolis: Vozes, 2003. p. 69-85.

BORDIGNON, Genuino; GRACINDO, Regina Vinhaes. Gestão da educação: o município e a escola. In: FERREIRA, Naura Syria Carapeto; AGUIAR, Marcia Ângela da S. (Org.). Gestão da educação: impasses, perspectivas e compromissos. São Paulo: Cortez, 2000. p. 147-176.

BORDENAVE, Juan E. Diaz. O que é participação? São Paulo: Brasiliense, 1985.

BRASIL. Constituição da República Federativa do Brasil de 1988, de 5 de outubro de 1988. Brasília: Senado Federal, 1988. Disponível em: <http://www.planalto.gov.br/ccivil_03/constituicao/ constituicao.htm>. Acesso em: 10 ago. 2016.

Lei no 9.394, de 20 de dezembro de 1996. Estabelece as diretrizes e bases da educação nacional. Diário Oficial [da] República Federativa do Brasil, Poder Executivo, Brasília, DF, 21 dez. 1996. Seção 1, p. 27833-27841.

. Parecer CNE/CEB no 30, de 12 de setembro de 2000. Solicita pronunciamento, tendo em vista o Parecer CEB 04/2000. Homologado em 5 de outubro de 2000. Diário Oficial da União, Poder Executivo, Brasília, DF, 6 out. 2000. Seção 1, p. 25.

Lei no 13.005, de 25 de junho de 2014. Aprova o Plano Nacional de Educação - PNE e dá outras providências. Diário Oficial União, Poder Executivo, Brasília, DF, Edição Extra, nº 120-A, 26 jun. 2014. Seção 1, p. 1-8.

CIAVATTA, Maria. A construção da democracia pós-ditadura militar. In: FÁVERO, Osmar; SEMERARO, Giovanni (Org.). Democracia e construção do público no pensamento educacional brasileiro. 2. ed. Petrópolis: Vozes, 2003. p. 87-103.

COUTINHO, Carlos Nelson. A democracia na batalha das ideias e nas lutas políticas do Brasil de hoje. In: FÁVERO, Osmar; SEMERARO, Giovanni (Org.). Democracia e construção do público no pensamento educacional brasileiro. 2. ed. Petrópolis: Vozes, 2003. p. 11-39.

CUNHA, Luiz Antônio. Educação, estado e democracia no Brasil. 2. ed. São Paulo: Cortez; Niterói: EDUFF; Brasília: Flacso do Brasil, 1995.

CURY, Carlos Roberto Jamil. Prefácio. In: OLIVEIRA, Maria Auxiliadora Monteiro (Org.). Gestão educacional: novos olhares, novas abordagens. 2. ed. Petrópolis: Vozes, 2005. p. 9-10.

DOURADO, Luiz Fernandes. A escolha de dirigentes escolares: políticas e gestão da educação no Brasil. In: FERREIRA, Naura Syria Carapeto (Org.). Gestão democrática da educação: atuais tendências, novos desafios. 2. ed. São Paulo: Cortez, 2000. p. 77-95.

FALEIROS, Vicente de P. A política social do estado capitalista. 12. ed. Campinas: Cortez, 2009. 
FAORO, Raymundo. Os donos do poder: formação do patronato político brasileiro. 7. ed. São Paulo: Globo, 1987. 2 v.

GADOTTI, Moacir; JACOBI, Pedro R. Participação e descentralização: a experiência educacional de São Paulo na gestão Luiza Erundina. In: ANUÁRIO da Educação - 1994. Rio de Janeiro: Tempo Brasileiro, 1994. p. 237-260.

HÖFLING, Eloisa de Mattos. Estado e políticas (públicas) sociais. Cadernos Cedes, ano XXI, n. 55, p. 30-41, nov. 2001.

IANNI, Octavio. Pensamento social no Brasil. Bauru: EDUSC, 2004.

JACOBI, Pedro Roberto. Educação, ampliação da cidadania e participação. Educação e Pesquisa, São Paulo, v. 26, n. 2, p. 11-29, jul./dez. 2000.

KRAWCZYK, Nora Ruth. Em busca de uma nova governabilidade na educação. In: OLIVEIRA, Dalila Andrade; ROSAR, Maria de Fatima Felix (Org.). Política e gestão da educação. 2. ed. Belo Horizonte: Autêntica, 2008. p. 61-74.

KRAWCZYK, Nora Ruth; VIEIRA, Vera Lucia. A reforma educacional na América Latina nos anos de 1990: uma perspectiva histórico-sociológica. São Paulo: Xamã, 2008.

LE BOTERF, Guy. A participação das comunidades na administração da educação. Revista de Administração Pública, Rio de Janeiro, v. 16, n. 1, p. 107-142, jan./mar. 1982.

LIMA, Licínio. A escola como organização educativa. 2. ed. São Paulo: Cortez, 2003.

A avaliação institucional como instrumento de racionalização e o retorno à escola como organização formal. Educação \& Pesquisa, São Paulo, v. 41, n. esp., p. 1339-1352, dez. 2015.

MENDONÇA, Erasto Fortes Mendonca. A regra e o jogo: democracia e patrimonialismo na educação brasileira. Campinas: LaPPlanE/FE/Unicamp, 2000.

MOISÉS, José Álvaro. Os brasileiros e a democracia: bases sócio-políticas da legitimidade democrática. São Paulo: Ática, 1995.

NEVES, Lucia Maria Wanderley. As massas trabalhadoras começam a participar do banquete, mas o cardápio é escolhido à sua revelia, ou democracia e educação escolar nos anos inicias do século XXI. In: FÁVERO, Osmar; SEMERARO, Giovanni (Org.). Democracia e construção do público no pensamento educacional brasileiro. 2. ed. Petrópolis: Vozes, 2003. p. 163-174.

NOGUEIRA, Marco Aurélio. Democracia participativa. In: GIOVANNI, Geraldo di; NOGUEIRA, Marco Aurélio (Org.). Dicionário de políticas públicas. 2. ed. São Paulo: Ed. Unesp; Fundap, 2015. p. 247-252.

OLIVEIRA, Dalila Andrade. A gestão democrática da educação no contexto da reforma do Estado. In: FERREIRA, Naura Syria Carapeto; AGUIAR. Marcia Ângela da S. (Org.). Gestão da educação: impasses, perspectivas e compromissos. São Paulo: Cortez, 2004. p. 91-112.

OLIVEIRA, Francisco de. Queda da ditadura e democratização no Brasil. In: FÁVERO, Osmar; SEMERARO, Giovanni (Org.). Democracia e construção do público no pensamento educacional brasileiro. 2. ed. Petrópolis: Vozes, 2003. p. 41-51. 
PARO, Vitor. Gestão democrática da escola pública. São Paulo: Ática, 1997.

SANTOS JUNIOR, Orlando Alves dos; RIBEIRO, Luiz Cesar de Queiroz; AZEVEDO, Sergio de. Democracia e gestão local: a experiência dos conselhos municipais no Brasil. In: . (Org.). Governança democrática e poder local: a experiência dos conselhos municipais no Brasil. Rio de Janeiro: Revan; Fase, 2004. p. 11-56.

SAVIANI, Dermeval. Política e educação no Brasil: o papel do congresso nacional na legislação do ensino. 6. ed. Campinas: Autores Associados, 2006.

História das ideias pedagógicas no Brasil. 2. ed. Campinas: Autores Associados, 2008.

STRECK, Danilo Romeu; ADAMS, Telmo. Lugares da participação e formação da cidadania. Revista de Ciências Sociais, Porto Alegre, v. 6, n. 1, p. 95-117, jan./jun. 2006.

VEIGA, Ilma Passos de Alencastro. Projeto político-pedagógico da escola: uma construção coletiva. In: VEIGA, Ilma Passos de Alencastro (Org.). Projeto político-pedagógico da escola: uma construção possível. 7. ed. Campinas: Papirus, 1995. p. 11-35.

WEFFORT, F. C. Por que democracia? 2. ed. São Paulo: Brasiliense, 1984. 